\title{
Práticas Possíveis com a História Oral na Formação Inicial de Professores (de Matemática)
}

\author{
Possible Practices with the Oral History in Initial Teacher Training (Math)
}

\author{
Vinícius Sanches Tizzo* \\ Flávia Cristina Gomes Flugge** \\ Heloisa da Silva ${ }^{* * *}$
}

\begin{abstract}
Resumo
Este artigo versa sobre resultados e discussões de duas pesquisas vinculadas a um projeto maior intitulado História Oral, Narrativas e Formação de Professores: pesquisa e intervenção. O primeiro estudo objetivou elaborar uma compreensão sobre as contribuições, limitações e potencialidades da História Oral como uma abordagem didático-pedagógica na disciplina Política Educacional Brasileira, a partir de uma intervenção junto a essa disciplina do curso de licenciatura em Matemática da Unesp/Rio Claro. E a segunda pesquisa buscou tecer uma compreensão sobre como a abordagem narrativa e da História Oral pode contribuir em disciplinas envolvendo matemática e seu ensino em cursos de Pedagogia, no trabalho de colocar os futuros professores em situações que os possibilitem um contato com o cotidiano das escolas e ampliem as possibilidades de discussão sobre práticas de ensino de matemática, para essa empreitada, a disciplina escolhida foi: Conteúdo, Metodologia e Prática do Ensino de Matemática, do curso de Pedagogia da Unesp/Rio Claro. Em linhas gerais, tais pesquisas sinalizam a abordagem da História Oral, por meio da mobilização de seus procedimentos, como uma prática profícua para auxiliar processos formativos voltados ao futuro professor (de Matemática), na medida em que permitiram um caminho de inscrição do percurso pessoal e profissional dos licenciandos na história, trazendo aportes para o desenvolvimento da compreensão crítica, no que tange à atuação desses futuros professores.
\end{abstract}

Palavras-chave: Narrativas. Licenciatura em Matemática. Pedagogia. Política Educacional Brasileira.

\begin{abstract}
This article deals with results and discussions of two related researches to a larger project entitled "Oral History, Narratives and Teacher Training: Research and intervention". The first study aimed to elaborate an understanding of the contributions, limitations, and potential of Oral History as a didactic-pedagogic approach for the Brazilian Educational Policy discipline, from an intervention with this discipline on the undergraduate course in Mathematics of Unesp/Rio Claro. The second research has sought an understanding of how the narrative and Oral History approach can contribute in courses involving mathematics and its teaching in

\footnotetext{
* Doutorando em Educação Matemática pela Universidade Estadual Paulista (Unesp/Rio Claro). Mestre em Educação Matemática pela Universidade Estadual Paulista (Unesp/Rio Claro). Endereço para correspondência: Av. 24-A, no. 1515, Bela Vista, CEP 13506-900, Rio Claro, São Paulo, Brasil. Email:viniciustizzo@hotmail.com.

${ }^{* *}$ Mestre em Educação Matemática pela Universidade Estadual Paulista (Unesp/Rio Claro). Endereço para correspondência: Rua 21, qd T, lote 1-25, no . 342, Vila Jaraguá, CEP 74655-090, Residencial Yes II, Goiânia, Goiás, Brasil. E-mail: flaviaflugge@gmail.com.

*** Doutora em Educação Matemática pela Universidade Estadual Paulista (Unesp/Rio Claro). Professora do Departamento de Educação Matemática e do Programa de Pós-graduação em Educação Matemática da Universidade Estadual Paulista, Rio Claro, São Paulo, Brasil. Endereço para correspondência: Av. 24-A, no . 1515, Bela Vista, CEP 13506-900, Rio Claro, São Paulo, Brasil. E-mail: heloisas@ @rc.unesp.br.
} 
pedagogy courses, even in the work place, with student and teachers in situations that allow contact and discussions about the daily life of schools and mathematics teaching practices and, with this objective in mind, the chosen discipline was: Content, Methodology, and Practice Teaching of Mathematics, related to the course of Pedagogy of Unesp/Rio Claro. Broadly, such surveys indicate the approach to oral history, through the mobilization of its procedures, as an useful practice to support training processes destined to future teachers (of Mathematics), in that they allowed an application path of personal and professional background of undergraduate in history, bringing contributions to the development of critical understanding regarding the work of these future teachers.

Keywords: Narratives. Mathematics Major. Pedagogy. Brazilian Educational Policy.

\section{Introdução}

Este texto apresenta resultados e discussões de duas pesquisas vinculadas a um projeto cujo objetivo foi elaborar e aplicar estratégias de formação de professores que ensinam matemática lançando mão da História Oral, bem como analisar tais estratégias ${ }^{4}$ e aplicação a partir de uma fundamentação na metodologia da História Oral praticada no interior do Grupo História Oral e Educação Matemática (Ghoem) ${ }^{5}$ (SILVA, 2010). Tal projeto, envolvendo pesquisa e intervenção, se deu no âmbito de disciplinas dos cursos de licenciatura em Matemática e Pedagogia da Universidade Estadual Paulista Júlio de Mesquita Filho, campus de Rio Claro. Neste texto tratamos das intervenções realizadas junto às disciplinas Política Educacional Brasileira, do curso de licenciatura em Matemática, e Conteúdo, Metodologia e Prática do Ensino de Matemática, do curso de Pedagogia, cujos dados foram analisados em Tizzo (2014) e Flugge (2015), respectivamente.

A ideia de realizar tal projeto surgiu com base nos resultados e nas possibilidades oferecidas pelos trabalhos fundamentados na metodologia da História Oral, no interior do Grupo História Oral e Educação Matemática - Ghoem, nos últimos treze anos. Tratam-se de investigações em que a História Oral, recente na Educação Matemática brasileira ${ }^{6}$, esteve amadurecendo discussões de forma representativa para a área, em especial no que tange à linha de pesquisa História da Educação Matemática, tratando, mais especificamente, de histórias relacionadas à formação de professores de matemática no Brasil ${ }^{7}$. Os trabalhos

\footnotetext{
${ }^{4}$ No âmbito da formação de professores, tais estratégias estão para o ensino e se constituem como percursos intencionalmente organizados de ações com vistas à sua eficácia, ou seja, à aprendizagem. Entendemos que a prática docente, ao longo de um processo de ensino, envolve a elaboração de várias estratégias e suas articulações e até reorientações de acordo com as conjunturas do grupo que se ensina.

5 www.ghoem.org.

${ }_{7}^{6}$ As pesquisas nessa abordagem surgem em 1999, e o Ghoem foi constituído em 2002 (SOUZA, 2006).

${ }^{7}$ Para conhecer tais pesquisas, ver Garnica (2014), uma coletânea de textos de pesquisadores do Ghoem que versam sobre as pesquisas por eles desenvolvidas nos últimos dez anos do grupo.
} 
desenvolvidos e em desenvolvimento nesse grupo têm as narrativas e os fundamentos sobre seu uso em pesquisas das humanidades como panos de fundo de suas práticas de pesquisa; e a História Oral tem sido, dentre as tantas possibilidades de compor essas narrativas, o modo mais comumente mobilizado por nós.

As discussões provenientes de tais pesquisas indicam que a atenção às narrativas orais de atores do sistema educativo (professores, ex-professores, dirigentes, funcionários etc.) permite o contato e discussão com várias áreas do conhecimento, suas abordagens, seus tons, seus autores, diferentes perspectivas e aspectos, compreensões de centros e margens; contribuindo amplamente no trabalho de análise sobre como se deram ou têm se dado formações e atuações de professores que ensinaram/ensinam matemática ${ }^{8}$ em regiões e épocas variadas do Brasil (GARNICA, 2012). Tais pesquisas mostram, ainda, de que forma o referencial teórico-metodológico da História Oral admite o estabelecimento de conexões entre significados de narrativas orais e escritas e da própria historiografia para uma discussão daquilo que tende a permanecer e daquilo que tende a se alterar em práticas cotidianas de formação de professores de Matemática no Brasil.

Juntando-se a isso, no âmbito da Educação brasileira, já são muitas as pesquisas que têm empreendido um intenso investimento em teorizações sobre os cuidados e práticas relacionadas à utilização das narrativas, constituídas a partir de testemunhos orais ou produzidas na forma escrita, em processos de formação inicial e continuada de professores (ABRAHÃO, 2004; SOLIGO; PRADO, 2008; CORDEIRO; SOUZA, 2010). De modo análogo, especificamente na área de atuação da Educação Matemática, os trabalhos de Fiorentini (2006); Megid e Fiorentini (2011); Nacarato e Passeggi (2013); Silva (2013); Silva, Baraldi e Garnica (2013); Garnica (2014); Gomes (2014), entre muitos outros, revelam algumas das múltiplas investigações relacionadas à formação de professores (de Matemática) cuja tônica está centrada no trabalho com narrativas.

Como já ressaltamos (SILVA, 2013; GARNICA, 2014), os estudos desenvolvidos no âmbito da Educação Matemática que contemplam a conexão entre narrativas e formação de professores têm sido comumente concebidos e desenvolvidos por meio de bases teóricometodológicas variadas, muitas vezes sendo constituídos e sustentados por diferenciados gêneros narrativos, envolvendo tanto a oralidade quanto a escrita e, dependendo do foco de

\footnotetext{
${ }^{8}$ Assim como Fiorentini et al. (2002) utilizaremos a denominação de professores que ensinam matemática para contemplar este professor da Educação Infantil e das séries iniciais do Ensino Fundamental que atua no ensino desta área de conhecimento.
} 
pesquisa, usadas de modos que também variam. Todavia, independente dos diferentes modos de apropriação das narrativas, o fio condutor comum a todas as fundamentações em narrativas de sujeitos da educação, tem sido a experiência humana.

No Ghoem, o trabalho com as narrativas da experiência tem sido explicitamente realçado pela dimensão histórica, justamente pelos interesses de pesquisa do grupo e, nesse sentido, Ricoeur (2000) e Bolívar, Domingo e Fernández (2002) têm nos respaldado. De acordo com esses autores, a narrativa pode ser considerada como uma possibilidade de rompimento da incomunicabilidade da experiência, isto é, a narrativa pode ser compreendida como uma reconstrução de experiências. Para Bolívar, Domingo e Fernández (2002), na elaboração de uma narrativa, por meio de um processo reflexivo, se atribui significado ao vivido, ao experienciado. Segundo Ricoeur (2000), o relato narrativo é, assim, uma forma particular de discurso, organizado em torno de uma trama argumentativa, a qual apresenta uma sequência temporal, personagem(ns) e situações os quais fazem com que enunciados tenham sentido no contexto do argumento. Como afirmou Gomes (2014, p. 197), "o estudo de Ricoeur enfatiza, portanto, a relação entre historiografia e narração. Mesmo que nem todo trabalho que associa narrativas e formação de professores (de Matemática) realce ou valorize explicitamente a dimensão histórica, ela está inevitavelmente presente neles”.

Assim, alguns resultados desse primeiro projeto debruçado na elaboração, aplicação e análise de estratégias com a utilização da História Oral (HO) na/para a formação inicial de professores que ensinam matemática, vêm indicar, por meio das pesquisas supracitadas e discutidas neste texto, algumas contribuições, limites e potencialidades do uso da $\mathrm{HO}$ em processos formativos de professores que ensinarão matemática. A seguir, indicamos nosso cuidado com a problematização dos contextos em que se deram essas pesquisas para, em seguida, apresentar e discutir suas respectivas propostas e resultados.

\section{Das intervenções em cursos de licenciatura: considerações necessárias}

Neste texto, aspiramos apresentar (e ressaltar) as possibilidades e potencialidades ${ }^{9}$ dos vínculos estabelecidos entre a formação de professores que ensinarão matemática e a História Oral. Para tanto, mobilizamos os casos particulares da formação inicial de professores dos cursos de licenciatura em Matemática e da Pedagogia da Unesp/Rio Claro, reportando-nos às

\footnotetext{
${ }^{9} \mathrm{O}$ termo potencialidade é compreendido em seu sentido amplo, ou seja, como característica daquilo que está em potência, que contém a possibilidade de vir a ser algo.
} 
atividades envolvendo o trabalho de produção e tratamento de narrativas, segundo os pressupostos metodológicos da $\mathrm{HO}$ em disciplinas desses cursos.

Como ressaltamos em Silva (2013), nos últimos anos, chama a atenção dos pesquisadores em Educação Matemática, um realce nas discussões sobre as questões teóricas relacionadas aos cursos de licenciatura em Matemática, em detrimento dos efeitos práticos que possibilitem mudanças efetivas em tais cursos. No Ghoem, entendemos e defendemos que os discursos acadêmicos, alusivos à temática formação de professores, apenas mostrarão força, se forem consideradas as circunstâncias específicas em que tais cursos são desenvolvidos, ou seja, conhecidas as especificidades de cada curso, por exemplo, suas legislações vigentes, instâncias institucionais, interesses individuas e coletivos, bem como suas histórias.

Também já citamos em Silva (2013) pesquisas da área (GOMES, 1997; GARNICA; MARTINS, 1999; OLIVEIRA; FRAGOSO, 2011; MOREIRA， 2012; MARTINSSALANDIM, 2012) que revelam tais características de determinadas instituições e, por isso, devem ser consideradas quando da implantação de novas propostas pedagógicas nesses espaços. Esses estudos, por refletirem sobre contextos específicos, legitimam o estudo de situações particulares e possibilitam o sustento de iniciativas que visem à elaboração de compreensões sobre ações pontuais no processo de formação de professores (de Matemática).

Em consonância com tais pressupostos, as pesquisas desenvolvidas por Tizzo (2014) e Flugge (2015) trazem contribuições sobre as histórias e circunstâncias das licenciaturas em Matemática e Pedagogia da Unesp, Campus de Rio Claro, âmbito em que as estratégias elaboradas e aplicadas com a História Oral e tais pesquisas se deram. Alguns aspectos envolvendo tais contextos encontram-se brevemente relatados nas seções subsequentes deste texto, mas por motivos de espaço e objetivos, não detalhamos os aspectos históricos de tais disciplinas.

Não obstante, é de sensível cuidado, como indicado no estudo de Tizzo e Silva (2013), compreender que uma determinada pesquisa, ao lançar-se ao estudo referente a uma situação específica de ensino, essencialmente deve ser regida sob pressupostos claros para se evitar uma sumária experimentação. Estabelecendo uma estreita proximidade com tais indicações, as intervenções descritas em Tizzo (2014) e Flugge (2015), envolvendo estudantes das licenciaturas supracitadas e professora envolvida, constituíram-se como estratégias de ensino cuidadosamente pensadas para cada um desses contextos disciplinares. Para tanto, foi analisado um amplo repertório de referências e, posteriormente, sugerida/proposta uma 
abordagem e estratégias que foram potencialmente significativas para as turmas das respectivas disciplinas. Nesse sentido, as pesquisas não buscaram compreender se as propostas lograram êxito ou não, mas entender como funcionaram, isto é, os trabalhos empreenderam esforços em alçar compreensões sobre a implementação dos recursos da História Oral no processo de formação inicial de professores que ensinarão Matemática, buscando expor as possibilidades, as limitações e as potencialidades de tal proposta, nesses casos específicos.

Nessa direção, a proposta das seções que se seguem se delineia com vistas à exposição de algumas possibilidades, limitações, e potencialidades da utilização da HO no processo de formação de professores que ensinarão Matemática. Além disso, visa colaborar com o propósito pela busca da constituição de um referencial consistente sobre a abordagem da $\mathrm{HO}$ na (e para a) formação de professores (de Matemática), um dos interesses do projeto a que tais pesquisas estiveram vinculadas. Assim, em cada uma delas são apresentados, brevemente, os contextos das pesquisas que hospedaram e fomentaram os trabalhos de Tizzo (2014) e de Flugge (2015); uma descrição das respectivas intervenções realizadas; e, por fim, uma exposição de algumas compreensões sobre os aspectos emergentes das respectivas pesquisas.

\section{A HO como uma abordagem didático-pedagógica na disciplina Política Educacional}

\section{Brasileira de um curso de licenciatura em Matemática}

A pesquisa de Tizzo (2014) teve por objetivo elaborar uma compreensão sobre as contribuições da $\mathrm{HO}$ como uma abordagem didático-pedagógica, para a disciplina Política Educacional Brasileira (PEB) na formação do professor de Matemática, a partir de uma intervenção em tal disciplina do curso de licenciatura em Matemática da Unesp, Campus de Rio Claro. Para tanto, o pesquisador esteve envolvido desde a elaboração até a aplicação e análise de estratégias com a $\mathrm{HO}$ pensadas para tal disciplina.

O passo inicial foi uma familiarização com tal contexto disciplinar por meio do estudo do projeto pedagógico do curso, bem como do histórico e programa da disciplina. O segundo passo foi estabelecer contato e parceria com a professora que ministrava essa disciplina na ocasião. Em seguida, e com o apoio da professora responsável, passou-se ao processo de elaboração das estratégias com a HO e aplicação em tal disciplina.

Política Educacional Brasileira é uma disciplina de caráter obrigatório, ministrada, geralmente, no primeiro semestre de cada ano e recomendada aos estudantes que estejam 
cursando o quarto ano do curso de licenciatura. O aluno que cursa essa disciplina deve, obrigatoriamente, perfazer uma carga horária de 90 horas. Embora seja uma disciplina ministrada aos acadêmicos do curso de Licenciatura em Matemática, o departamento de Educação é o responsável pelo oferecimento e manutenção da disciplina. O programa dessa disciplina, apresentado no projeto político-pedagógico do curso de Matemática da Unesp/Rio Claro, prevê que sejam abordados conteúdos que proporcionem uma reflexão sobre a organização burocrática da sociedade moderna; a escola como uma organização complexa e burocrática; a política educacional brasileira e legislação; a política de funcionamento; o professor e os critérios de avaliação.

$\mathrm{Na}$ pesquisa, por meio de uma parceria estabelecida entre os pesquisadores ${ }^{10}$ e a professora responsável pela disciplina $\mathrm{PEB}^{11}$, buscou-se envolver os licenciandos, futuros professores de Matemática, em situações relacionadas à sua futura atuação docente, tendo em vista uma dupla função para HO: como estratégia de intervenção - na disciplina PEB do curso de licenciatura em Matemática - e como método de análise dos dados constituídos. Nessa segunda função, os pressupostos metodológicos da $\mathrm{HO}$ auxiliaram o pesquisador na elaboração de uma compreensão sobre os resultados da estratégia que foi proposta para formar professores de Matemática (GOMES; TIZZO; SILVA, 2013).

Com a motivação da possibilidade de alinhamento entre as intenções de pesquisa e os objetivos da disciplina PEB, previstos no programa do curso de licenciatura em Matemática da Unesp/Rio Claro ${ }^{12}$, a intenção do pesquisador nessa empreitada esteve mais diretamente relacionada à possibilidade de ampliação das compreensões, por parte dos estudantes, dos aspectos relacionados a cada temática, do que com relação à subversão da forma clássica com que os temas eram tratados no decorrer das aulas da disciplina PEB (por meio de leituras e discussões de documentos e artigos sobre a estrutura e o funcionamento do ensino, que comumente caracteriza a abordagem das temáticas inerentes a educação no processo de formação de professores). Embora argumentamos favoravelmente sobre a defesa da necessidade do estudo de fontes outras, de naturezas variadas, reconhecemos que cada forma

\footnotetext{
${ }^{10}$ Heloisa da Silva e Vinícius Sanches Tizzo, respectivamente orientadora e orientando.

${ }^{11}$ Prof $^{\mathrm{a}}$. Dr ${ }^{\mathrm{a}}$. Marilena Aparecida Jorge Guedes de Camargo.

12 O programa de PEB, no curso em que Tizzo (2014) desenvolveu suas atividades, prevê que o futuro professor, a partir das discussões durante as aulas, seja capaz de, dentre outros aspectos: analisar com a necessária fundamentação teórica as atuais políticas públicas para a educação; refletir sobre a problemática da educação, enfatizando a educação fundamental e média, numa perspectiva de totalidade, aprendendo seus determinantes sociais, econômicos, políticos e culturais; identificar a relação entre a política educacional e a organização e o funcionamento da unidade escolar.
} 
de trabalho possui sua possibilidade, limitação e sua potencialidade, por isso a integração de formas diferentes de abordagem de um determinado tema, pode favorecer a ampliação das possibilidades de aprendizagem (TOGURA; SOUZA, 2012).

Assim, para o trabalho com a HO na disciplina PEB, foram elencadas, com a ajuda da professora responsável, temáticas a partir das quais os alunos desenvolveriam estudos pautados em uma atividade devidamente estruturada para aquela disciplina. Foram as temáticas: Educação e Política no Brasil; Memória: alguns aspectos da política educacional brasileira; Debate entre Exclusão e Inclusão; Educação x Professor de Matemática: métodos avaliativos no âmbito da sala de aula e cotidiano; Violência nas escolas. Esses cinco temas foram trabalhados, separadamente, por seis grupos de estudantes, sendo o tema Violência nas escolas selecionado e estudado por dois grupos diferentes.

De maneira sintética, a atividade proposta envolveu nove momentos, pautados em procedimentos comumente utilizados em pesquisas em HO: 1) apresentação e discussão dos fundamentos e procedimentos da $\mathrm{HO}$ aos alunos da disciplina; 2) escrita de memória do grupo sobre o tema - nesse momento, os acadêmicos foram induzidos a escrever um relato sobre seus interesses pelo tema escolhido e seus conhecimentos sobre ele, levantando questionamentos que gostariam de propor a um(a) professor(a) em serviço disposto(a) a conceder-lhes uma entrevista sobre o tema; 3) leituras de textos, fornecidos pelos pesquisadores e professora responsável, referentes ao tema em estudo; 4) elaboração de roteiro de entrevista a realizar-se com um(a) professor(a) em serviço; 5) contato e realização de entrevista com professor(a) em serviço; 6) transcrição das entrevistas gravadas; 7) textualização das transcrições; 8) legitimação das textualizações pelos entrevistados e assinaturas de cartas de cessão de direitos sobre tais textualizações; 9) apresentação do estudo para a turma de alunos da disciplina.

Tal proposta esteve pautada na ideia de que no processo formativo do futuro professor (de Matemática), seria significativo, de algum modo que o futuro docente usufruísse de ocasiões em que se deparasse, durante os anos do curso de formação, com um espaço em que as circunstâncias "e (suas) vivências pessoais, de sala de aula ou não, relativas aos conteúdos específicos ou não, possam ser problematizadas e reavaliadas para posteriormente serem adaptadas como parte integrante de suas práticas" (SILVA, 2013, p. 272-273).

Com base em tal argumentação, consideramos imprescindível que a formação inicial do professor (de Matemática) contemple não só o contato do acadêmico de licenciatura com a teoria de sua área de atuação, mas que, ao longo do curso, esse futuro docente, tenha a 
oportunidade de interagir com o próprio professor da disciplina específica na universidade e também com profissionais docentes que atuam em outras instâncias de ensino que precedem a educação superior.

Se por um lado a necessidade é o mote da aprendizagem, por outro é preciso saber onde satisfazê-la, isto é, onde aprender. E talvez não seja demais afirmar que é observando alguém mais experiente naquilo que queremos fazer que podemos aprender mais rapidamente e fazer também. Se alguém, além de se deixar observar em ação, faz o papel de parceiro experiente, então as possibilidades se ampliam ainda mais (SOLIGO; PRADO, 2008, p. 31).

Nesse sentido, tal proposta buscou veicular o uso de estratégias de formação que colocassem professores e futuros professores em maior contato com estruturas e tendências educacionais que os ajudassem a compreender os significados de determinadas situações de sala de aula e da escola que, ainda que sejam singulares e não suas, os possibilitassem o contato com narrativas de experiências que poderiam ser suas, fazendo-os refletir sobre decisões que terão de tomar rotineiramente ao iniciar sua docência ou em algum momento dela (TIZZO; SILVA, 2013).

\subsection{Das etapas da intervenção - alguns resultados}

Uma das etapas iniciais da intervenção didático-pedagógica, proposta aos estudantes da disciplina PEB, foi o processo de estudos e elaboração do roteiro sobre cada tema com a supervisão da professora e dos pesquisadores. Tal atividade expôs um intenso trabalho de pesquisa sobre as temáticas a serem investigadas por eles. Em seguida, o procedimento de transcrição das entrevistas pelos acadêmicos (seis, no total), se configurou como um processo de nova escuta e, portanto, nova compreensão do relato dos professores. Posteriormente, durante a elaboração da textualização, os acadêmicos estiveram envolvidos em pesquisas sobre os significados de termos, conceitos, siglas, dentre outros, para alimentarem a textualização enquanto um documento histórico, por meio de notas de rodapé.

Com o procedimento de textualização das entrevistas, a pretensão foi envolver os acadêmicos em uma situação de análise, ou de outro modo, na elaboração de uma compreensão sobre os relatos, similar à análise do pesquisador ao textualizar suas entrevistas, em consonância com os pressupostos metodológicos da $\mathrm{HO}$, isto é, o pesquisador, ao textualizar, o faz com os olhos de quem analisa determinado(s) fenômeno(s) - ou seja, busca responder determinadas questões de cunho histórico, prático ou teórico - e esse processo o ajuda a relacionar as experiências (ou fatos) contadas (os) às discussões teóricas já estudadas, 
conduzindo-o a novas análises e considerações sobre o tema pesquisado. Tizzo (2014) argumenta que tal atividade estimulou a incorporação de uma postura investigativa por parte dos acadêmicos e, nesse sentido, compreendeu que a formação inicial desse professor é um momento adequado para o incentivo dessa prática, que poderá ser complementada no decorrer do desenvolvimento de suas atividades profissionais.

O desfecho da intervenção didático-pedagógica proposta na disciplina PEB culminou na exposição dos alunos sobre suas impressões com relação à proposta de trabalho, por meio de uma apresentação na aula final da disciplina PEB e, posteriormente, durante a gravação de entrevistas com cada grupo de estudantes que trabalhou uma determinada temática. Em tais oportunidades, os acadêmicos revelaram que esta foi uma forma diferenciada de se trabalhar os temas da disciplina de PEB, isto é, as aulas da disciplina não foram desenvolvidas apenas com leituras e discussões de textos. Dessa forma, os acadêmicos da disciplina PEB reconhecem que a intervenção didático-pedagógica com vistas à mobilização dos recursos da HO promoveu uma articulação entre o modo com que os temas, tradicionalmente, seriam trabalhados na disciplina e a proposta de estudo envolvendo a $\mathrm{HO}$, já que, os textos que foram trabalhados durante as aulas, subsidiaram a estruturação dos roteiros de questões para as entrevistas.

Os estudantes também afirmaram que, sem essa atividade, perderiam a chance de trocar informações com profissionais ligados à escola sobre assuntos diretamente relacionados a tal ambiente. Para Natália, por exemplo, que foi uma das alunas da disciplina PEB envolvida na atividade ${ }^{13}$ :

Na universidade estamos acostumados apenas a consultar livros, autores. Essa proposta de trabalho com entrevistas é uma forma de investigar o que os profissionais estão vivendo no nosso futuro local de trabalho, a escola. Nesse sentido, imagino que essas pessoas têm muito a contribuir com a nossa formação. Acredito que todas as disciplinas da licenciatura em Matemática poderiam trabalhar seus temas através de uma abordagem como essa.

A narrativa de Fernanda, uma segunda aluna envolvida na atividade de formação ${ }^{14}$, corrobora as afirmações de Natália, isto porque, para ela: "Aqui na universidade não temos muitas chances de conhecer a escola, trabalhar na escola. Foi uma ótima oportunidade para vermos como ela funciona, como são os problemas que os professores e os alunos enfrentam diariamente".

\footnotetext{
${ }^{13}$ Natalia trabalhou com a temática Memória: alguns aspectos da política educacional brasileira.

${ }^{14}$ Fernanda fez dupla com o aluno Bruno e juntos trabalharam a temática Violência nas Escolas.
} 
O trabalho realizado pelos alunos Noemi e Tiago com a temática: Debate entre a Exclusão e a Inclusão, traduz fortemente a importância desse contato entre os alunos dos cursos de licenciatura e profissionais mais experientes. No início da atividade, Noemi e Tiago, empreenderam um esforço, durante a elaboração do roteiro de questões, em explorar os aspectos negativos ligados ao processo de inclusão. Entretanto, a narrativa que constituíram, a partir da entrevista realizada com uma professora ligada a área de Educação Inclusiva, revelou novos aspectos relativos ao tema, que não foram abarcados nas leituras que realizaram anteriormente. Assim, houve uma tomada de consciência por parte dos acadêmicos Noemi e Tiago, que passaram a compreender como se dá o processo de inclusão de um aluno em uma sala de aula. Segundo Noemi: “durante nossa carreira como professores, estaremos em contato com alunos que terão necessidades especiais e essa foi uma maneira de esclarecermos muitas de nossas dúvidas sobre o assunto".

Segundo Michel e Renata, que trabalharam com o tema: Educação x Professor de Matemática: Métodos Avaliativos no Âmbito da Sala de Aula e Cotidiano, com a intervenção proposta, além de terem tido acesso aos recursos de uma metodologia de pesquisa, a $\mathrm{HO}$, tiveram oportunidade de entrar em contato com um profissional da Educação, mais experiente que falou sobre seus métodos de avaliação. De modo que, para Michel, nessa atividade, o que merece destaque é:

A possibilidade de conhecermos um professor que está atuando em sala de aula, de conhecermos a opinião desse professor sobre o processo de avaliação no cotidiano escolar. A entrevista, a transcrição e a textualização possibilitaram que tivéssemos esse contato com a opinião do professor.

Ao serem interrogados pelo pesquisador sobre os procedimentos metodológicos utilizados, esses estudantes declararam que o método empregado para o desenvolvimento da atividade lhes permitiu conhecer aspectos novos sobre o tema, pensar sobre as respostas do professor entrevistado, sobre seus enfrentamentos do cotidiano com relação à temática, principalmente durante o processo de textualização da entrevista. Inclusive, nessa etapa, houve a necessidade de os estudantes incorporarem um exercício de investigação sobre informações de diversas declarações do depoente, como, por exemplo, no caso da aluna Natalia, que relatou um intenso trabalho de investigação para inserir os significados, em notas de rodapé, na própria textualização, sobre expressões que não conhecia, tais como: Neoliberalismo, Estado Mínimo, Mais - Valia, Progressão Continuada, Investimento a Fundo Perdido, entre outros. 
A incorporação do trabalho com a $\mathrm{HO}$ e narrativas ao plano de atividades da disciplina PEB é uma defesa que podemos observar no depoimento da professora Marilena, responsável pela disciplina, isto porque, segundo ela:

[...] incluindo a História Oral no seu currículo, essa disciplina apresentaria não só uma novidade, mas melhoraria nos resultados de aprendizagem, já que haveria no trabalho com entrevistas uma ampliação da visão da realidade e, por certo, um novo passo na concretização de conquistas. Seria um avanço significativo porque calculo que as entrevistas são resultados da História, da época de uma sociedade que a produziu.

A título de finalização desta seção, avaliamos que as atividades propostas aos acadêmicos da disciplina PEB serviram para sensibilizar os licenciandos para as disciplinas pedagógicas. O trabalho com narrativas de profissionais em serviço sobre suas vivências de formação e seus enfrentamentos com relação a cada tema estudado possibilitou aos acadêmicos se reportarem à posição de profissionais e refletirem sobre como agir em situações como as vivenciadas e relatadas por seus entrevistados. Como reconhece Tizzo (2014), outros elementos, certamente, poderiam ser agregados a esse estudo, entretanto, sob o propósito de ampliar as possibilidades de elaboração de compreensões sobre as potencialidades de problematização da $\mathrm{HO}$ e das narrativas no processo de formação de professores (de Matemática). Pois, o processo jamais se esgota.

\section{A abordagem da História Oral na disciplina Conteúdo, Metodologia e Prática do Ensino de Matemática em um curso de Pedagogia}

A disciplina Conteúdo, Metodologia e Prática do Ensino de Matemática - CMPEM do curso de Pedagogia da Unesp, Campus de Rio Claro, foi escolhida como um dos campos de atuação do Projeto História Oral, Narrativas e Formação de Professores: pesquisa e intervenção pela segunda e terceira pesquisadoras, autoras deste texto. A pesquisa de Flugge (2015), nesse contexto, teve por objetivo tecer uma compreensão sobre como a abordagem narrativa e da $\mathrm{HO}$ pode contribuir em disciplinas envolvendo matemática e seu ensino em cursos de Pedagogia, no trabalho de engajar os futuros professores em situações que os coloquem em contato com o cotidiano das escolas e ampliem as possibilidades de discussão sobre as práticas de ensino de matemática.

A partir dessa tessitura, buscamos destacar, nesta seção, algumas estratégias elaboradas e aplicadas nessa disciplina por sua professora e terceira autora deste texto, bem como a análise de suas potencialidades e possibilidades nesse contexto de formação, 
desenvolvida por Flugge (2015), cujo papel da HO, assim como em Tizzo (2014) foi o de instrumento de intervenção e metodologia da pesquisa realizada.

A disciplina CMPEM é a única do referido curso envolvendo questões relativas à Matemática e seu ensino, sendo oferecida no terceiro período por professores do Departamento de Educação Matemática, sendo de caráter obrigatório. A carga horária dessa disciplina é composta por $75 \mathrm{~h}$, dividida entre $60 \mathrm{~h}$ de aulas teóricas e $15 \mathrm{~h}$ de prática. Seu programa sugere: o tratamento das quatro grandes áreas propostas nos Parâmetros Curriculares Nacionais (grandezas e medidas; números e operações; forma e geometria; tratamento da informação); tendências e abordagens da Educação Matemática (por exemplo: modelagem, resolução de problemas, investigações, etnomatemática, computadores e calculadoras, educação matemática crítica e diversidade cultural); jogos e materiais didáticos manipulativos; análise e uso de livros didáticos e paradidáticos; processos de interação e comunicação online (onde possível e adequado).

Considerando a proposta da disciplina em questão, foram elaboradas, pela professora responsável, estratégias pedagógicas visando favorecer a problematização e discussão dos sentidos para si, por parte dos estudantes, como futuros profissionais, e a mobilização de suas noções, das noções dos colegas, de profissionais do ensino, de pesquisadores da área da educação matemática, de instituições governamentais e daquelas apresentadas pela professora sobre a Matemática e seu ensino. Nessa disciplina, portanto, a integração da HO à sua abordagem de ensino se deu com vistas à prática profissional de futuros professores pedagogos, que ensinarão matemática nas séries iniciais do Ensino Fundamental.

A seguir, descrevemos a intervenção na disciplina CMPEM, detalhando as estratégias e as atividades elaboradas com a HO, isto é, seus objetivos e o modo como elas se deram, e, por fim, aventamos alguns resultados ${ }^{15}$.

\subsection{Estratégias e intervenção}

A participação da pesquisadora, segunda autora deste texto, se deu em seu acompanhamento presencial durante as aulas, pela plataforma do Moodle - em ambiente

\footnotetext{
${ }^{15}$ Ressaltamos que as atividades propostas durante a disciplina não envolveram somente estratégias de ensino com a HO. Também foram realizadas aulas expositivas sobre conteúdos matemáticos do Ensino Fundamental, aplicação de sequência de atividades matemáticas, estudos e análises de materiais didáticos e narrativas autobiográficas escritas. Porém, considerando os objetivos deste texto, destacamos as atividades que envolveram diretamente estratégias com o uso dos recursos da HO.
} 
virtual conectado à Internet - criada para a disciplina, no auxílio aos estudantes em suas atividades e dúvidas. Também realizou estudos de documentos que envolviam o curso e a disciplina, como o Projeto Político Pedagógico e os Programas da Disciplina (1999 - 2006), e acompanhamento das atividades e estratégias aplicadas pela professora.

A disciplina era semanal, e a cada semana havia tarefas e atividades vinculadas às narrativas e à $\mathrm{HO}$ a serem realizadas em períodos extraclasse, que eram discutidas em sala de aula. A constituição dos dados da pesquisa de Flugge (2015) se deu a partir desse material, disponibilizado na disciplina, dessas atividades e de entrevistas com alguns grupos de alunos, selecionados para tal fim, questionando sobre o que consideravam e a forma que entendiam o desenvolvimento das atividades que envolviam as narrativas e a $\mathrm{HO}$.

Destacamos, para este texto, uma atividade que envolveu mais especificamente a $\mathrm{HO}$, chamada Trabalho Final ${ }^{16}$. Apresentamos as etapas que a envolveram, seus objetivos e o modo como foram desenvolvidas; por fim, as potencialidades e possibilidades apresentadas por meio dessa atividade.

A atividade Trabalho Final foi dividida em cinco etapas, iniciadas no segundo mês de aulas, e a partir da divisão da turma em grupos de estudantes para estudos de temas matemáticos por eles escolhidos ${ }^{17}$. Foram cinco as etapas: 1) escrita de uma memória do grupo sobre o seu conhecimento prévio do tema; 2) estudo da temática escolhida a partir de materiais disponibilizados pela professora e escrita de um resumo sobre o tema, seguida da apresentação de um roteiro de perguntas para realização de entrevista com um professor de Matemática ou que ensina Matemática; 3) compreensão de alguns procedimentos da HO para preparação, realização e tratamento da entrevista (transcrição e textualização); 4) escrita individual de texto sobre as etapas precedentes do trabalho; 5) apresentação de seminário sobre o trabalho realizado pelo grupo. Nos parágrafos seguintes, abordamos as etapas ${ }^{18}$, junto com a descrição de seus encaminhamentos e resultados.

O objetivo da primeira etapa, memória do grupo, foi proporcionar aos acadêmicos um momento para que pensassem e relembrassem o que conheciam e quais ideias tinham do tema escolhido e em estudo. A estratégia aplicada foi a construção de um texto, por parte de cada um dos grupos, referente aos seus conhecimentos prévios sobre aquela temática escolhida,

\footnotetext{
${ }^{16}$ Essa atividade foi assim chamada por ser um trabalho avaliativo que encerraria a disciplina.

${ }^{17}$ Os temas trabalhados pelos diferentes grupos foram: 1) Grandezas e Medidas; 2) Geometria (Espaço e Forma);

3) Introdução à Ideia de Frações; 4) Operações de Adição e Subtração, 5) Operações de Multiplicação e Divisão;

6) Tratamento da Informação.

${ }^{18}$ Descrevemos somente sobre as três primeiras etapas desta atividade, até a fase da legitimação das entrevistas.
} 
contendo a justificativa da escolha do tema, os conhecimentos que o grupo já possuía sobre a temática, bem como do seu ensino e também um roteiro de questões que gostariam de fazer a um (a) professor (a) de Matemática, ou que ensina Matemática, interessado em ceder uma entrevista sobre essa temática.

Após essa construção, foi proposto aos acadêmicos um estudo de materiais (segunda etapa) disponibilizado pela professora, sobre as respectivas temáticas estudadas por cada grupo. Entre os materiais disponibilizados destacavam-se: dois artigos científicos; um material de formação continuada do Pró-Letramento; duas narrativas de professores, uma disponibilizada via textualização de entrevista e outra via vídeo e livro didático. O objetivo desta etapa foi possibilitar aos futuros pedagogos contato com uma diversidade de materiais disponíveis para o estudo da temática e o ensino, como as narrativas, livros didáticos e recursos como o vídeo; além, é claro, do acesso aos conhecimentos envolvidos na temática.

O encaminhamento foi o de que os grupos lessem e estudassem, juntos, esses materiais, e construíssem um relatório referente ao estudo realizado, indicando os pontos mais interessantes, o que não conheciam e foi novidade, ou que já conheciam, as partes que tiveram dificuldades de compreensão, e se havia alguma crítica ou discordância com os autores dos materiais. Nessa etapa também foi pedido para que os grupos revissem e, se fosse o caso, reescrevessem o roteiro de questões para a realização da entrevista com um professor, considerando o estudo realizado e as sugestões dadas pela professora.

Também nessa segunda etapa, constituiu-se a reconstrução do roteiro de entrevista e o primeiro passo do trabalho com os procedimentos da $\mathrm{HO}$, mais marcadamente. Seu objetivo foi o de promover uma oportunidade para os grupos exporem suas dúvidas e discussões que almejassem promover com um professor atuante em sala de aula. Sua elaboração inicial foi realizada a partir da memória do grupo, como já mencionamos anteriormente.

A etapa seguinte, consistiu no contato com o(a) professor(a) escolhido(a) para realização da entrevista. A professora responsável pela disciplina CMPEM, orientou os grupos de acadêmicos que o professor escolhido poderia ser de matemática ou que ensina matemática. Além disso, alertou os estudantes sobre a necessidade de entrega da carta de apresentação sobre o trabalho, carta que foi elaborada e assinada pela própria professora e entregue a cada um dos grupos.

Após a escolha do professor, a entrega da carta de apresentação e o aceite do profissional docente em conceder a entrevista, cada grupo marcou data, horário e local para a sua realização. Realizada a entrevista, para o tratamento da mesma, os estudantes foram 
orientados a utilizarem os procedimentos comumente trabalhados na $\mathrm{HO}$, isto é, a transcrição e, posteriormente, a textualização, os quais foram explicitados e exemplificados pela professora na plataforma Moodle.

O processo de tratamento das entrevistas, a transcrição, foi uma etapa da intervenção em que os estudantes da disciplina CMPEM tiveram a oportunidade de relembrar as falas da entrevista e estruturá-las em um texto escrito. A transcrição foi elaborada na íntegra, conservando tudo o que foi dito no momento da entrevista, incluindo os vícios de linguagem, pausas, ruídos. Essa etapa teve por objetivo, o qual é considerado de bastante importância para o entrevistador, que os grupos rememorassem as falas dos entrevistados em detalhes, tendo a oportunidade de refletir sobre cada resposta e analisar para si, por meio de seus questionamentos, aquilo que mais o marcou na fala do professor colaborador da entrevista.

Depois de concluída a transcrição, os estudantes realizaram a sua edição, procedimento conhecido na HO como textualização, e que, no caso da intervenção na disciplina CMPEM, teve por objetivo reorganizar a fala do depoente sem, no entanto, excluir as particularidades que a caracterizam, de modo a constituir um texto com mais fluência de leitura. Compreendemos que as textualizações das entrevistas tratam de histórias, de experiências, de narrativas sobre o modo como tais experiências se deram. Elas expõem os sentidos que, no presente, os depoentes estabelecem para as experiências que tiveram. Esse procedimento também permitiu um momento de remodelação para os acadêmicos, pois puderam organizar as falas do entrevistado, constituindo para si, por meio da releitura do material, a possibilidade de um novo olhar sobre a temática, além de uma nova experiência.

Silva (2010) afirma que o desenvolvimento da textualização pode ser visto como um processo em colaboração entre o entrevistado e o pesquisador-entrevistador. E que o entrevistador deve buscar realizá-la, de modo que aquilo que está sendo reescrito seja legitimado pelo entrevistado como sendo uma escrita que poderia ser sua. No momento da legitimação e finalização da textualização, trabalha-se com um novo objeto, o qual o entrevistado tem a oportunidade de ler, sugerir acréscimos e alterações, dando novos significados ao texto.

A carta de cessão é o instrumento final de legitimação, em que o entrevistado confirma e cede suas falas para o entrevistador e grupo de pesquisa utilizá-las. No caso da intervenção promovida na disciplina CMPEM, depois de realizada a textualização e corrigida pela professora, os acadêmicos voltaram a contatar os professores entrevistados, objetivando esse momento final de legitimação, por meio da assinatura da carta de cessão. 


\subsection{Alguns resultados da intervenção na disciplina CMPEM}

As estratégias descritas tinham um aspecto comum: colocavam os futuros profissionais frente a significados e reflexões sobre experiências. Compreendemos que, por tal aspecto, os estudantes da disciplina CMPEM mostraram-se atentos às manifestações e demonstraram interesse, estabelecendo uma postura de alerta perante as situações narradas. Além disso, embora não correspondendo totalmente às solicitações de usos das ferramentas tanto técnicas (relativas à plataforma Moodle) como propostas em atividades investigativas, os esclarecimentos e insistências da professora favoreceram vivências desses estudantes com pesquisa e constituição de materiais relativos à educação matemática, as quais avaliamos importantes tanto para o seu desenvolvimento acadêmico como profissional.

A primeira etapa do Trabalho Final, relativa à da memória do grupo, possibilitou que os acadêmicos da disciplina CMPEM ressignificassem suas experiências, as características pessoais de aprendizagem, o ensino a que foram submetidos durante o período escolar, os sentimentos sobre a temática, e a matemática em si, além de ter disparado reflexões sobre outras questões que envolvem o ambiente escolar por parte dos próprios acadêmicos. Percebemos essa atividade como uma parte importante ao que se constitui o trabalho como um todo, pois ao possibilitar a socialização de conhecimentos e experiências sobre o tema no grupo, os estudantes sentiram-se parte daquele estudo, envolvidos com ele por meio de suas historicidades.

Essa etapa também favoreceu um pensar sobre dificuldades de aprendizagem possíveis quanto àquele conteúdo, ao considerarem e discutirem suas próprias dificuldades. Isso possibilitou que elaborassem questões sobre modos de ensino alternativos para a aprendizagem de seus futuros alunos. Como a acadêmica Aline aventou em sua entrevista:

Acho que é sempre importante ter essa reflexão e, como as meninas falaram mesmo, olhar o passado como foi para nós. Eu que tive mais dificuldade, tentar não transferir isso para nossos alunos, fazer isso de um jeito que eles também não tenham tantas dificuldades, tentar corrigir de certa forma os erros que cometeram conosco, pensando em uma coisa melhor. Como podemos fazer para não acontecer assim com eles. Eu acho que foi legal, por isso.

$\mathrm{Na}$ segunda etapa, estudo dos materiais, analisamos que a diversidade de materiais disponibilizada favoreceu a construção de modos de operação no exercício de pesquisa, a criticidade e desenvolvimento dos estudantes no conhecimento sobre a temática, além de esclarecer dúvidas apresentadas no grupo, durante a primeira etapa do trabalho, e poderem retomar o roteiro de questões para entrevista com o professor em serviço. 
Destacamos, nessa etapa, a disponibilização do vídeo como um recurso que promoveu a visualização do contexto escolar com maior proximidade e clareza. Aline reflete sobre a discussão nele apresentada, que a fez perceber a importância de valorizar, como futura professora, o conhecimento que o aluno traz para a sala de aula e explorá-lo durante o ensino da matemática.

Então, foi um vídeo com um professor na escola e ele conversa com outras professoras sobre
suas experiências. No começo do vídeo, o narrador fala: "Dando uma aula". Porque tem
coisas muito interessantes, mostram como os alunos deles faziam uma conta, de um jeito que
não é aquele que nós estamos acostumados a ver, a pensar, de um jeito diferente, mas que
chegava ao mesmo resultado. Então, eu acho que isso foi o mais importante, o mais
interessante, que é deixar a criança pensar e explorar do jeito que ela acha, mesmo que não
seja daquele jeito que a gente ensina, bem mecânico, para que ela tenha sua própria
compreensão, não para que seja algo forçado. Acho que contribuiu para isso, para essa
reflexão, para o trabalho.

$\mathrm{Na}$ etapa inicial da constituição do roteiro para a entrevista, sem consultarem outros materiais, os estudantes buscaram verificar entre eles quais eram as questões que gostariam de saber de um professor, bem como sobre a sua prática. Nessa etapa, ressaltamos que a unidade do grupo possibilitou aos acadêmicos reconhecerem a si mesmos, destacarem e partilharem suas próprias dúvidas. A construção do roteiro propiciou que os acadêmicos da disciplina CMPEM retomassem suas vivências com a temática de estudo e, assim, pudessem esclarecer dúvidas e dificuldades que ainda não haviam sido resolvidas e, desse modo, pensar sobre a temática de uma nova forma. Posteriormente, após o estudo do material sobre o tema, a partir do primeiro roteiro, os grupos traçaram outro, retomando as questões e verificando, pelo material, se chegaram a ter novas dúvidas ou questões a fazer.

Ao construírem o roteiro para a entrevista e realizarem a entrevista com o professor, Aline, por exemplo, se surpreendeu, pois considerou, inicialmente, esse instrumento como limitado, mas que, ao contrário, favoreceu a entrevista. Por nunca ter realizado anteriormente uma atividade como essa, expressa ter sentido muito nervosismo, e o roteiro favoreceu a condução do processo. A entrevista promoveu reflexões e questionamentos sobre as falas do professor por parte dos acadêmicos, o que aparenta ter sido um momento que, sensivelmente, os tocou por não aceitarem tudo pronto, mas terem a oportunidade de se questionarem se aquela prática fazia sentido para eles ou precisavam repensá-la. Como reflete Aline:

Eu acredito que sim, que muitas das coisas tanto que nós paramos muitas vezes para falar: "Olha, isso a gente quer fazer igual". Como a Amanda também falou que outras coisas não, mas acho que é uma coisa muito pessoal também que tem que viver na prática, vale muita a teoria, só que tem que rever muito na prática e foi tudo válido tudo que o professor falou, principalmente para a reflexão. Concordando ou não, mas para pensarmos como podemos 
fazer ou como vamos fazer quando estivermos na pele dele, estiver lá dentro da sala de aula, porque é muito fácil também julgar. Mas nós não sabemos o que realmente ele vive lá hoje.

A transcrição e a textualização das entrevistas também foram consideradas etapas importantes no trabalho de Flugge (2015). Por meio delas, são registradas na escrita as emoções, reações, isto é, os detalhes que, muitas vezes, não são percebidos durante a entrevista. Amanda, outra estudante da disciplina que participou da intervenção proposta, afirmou ter parado para pensar com maior cuidado sobre o que o professor estava falando, quando realizou a transcrição e textualização, e considera que esses processos vão além de simplesmente ouvir e reescrever, pois existe um contato maior com o que se ouve pausadamente e se escreve, ou seja, é uma segunda oportunidade de compreender e pensar sobre o que foi dito.

Nossas análises identificaram uma variedade de experiências vivenciadas por meio de cada etapa que compôs essa atividade e abordagem. Reconhecemos que as experiências relatadas destacam aprendizagens e remontam aspectos que configuram os entendimentos sobre a matemática e seu ensino pelos estudantes. A proposta com a abordagem da $\mathrm{HO}$ proporcionou contato com vivências de outras pessoas, orais e escritas, permitindo reflexões e questionamentos favoráveis às atuações dos futuros professores que ensinarão matemática.

A temática de estudo também foi além de se conhecer somente sobre tal tema, pois percebemos que todo entendimento de matemática foi trabalhado, auxiliando na desmistificação das dificuldades desses acadêmicos com a matemática e seu futuro ensino, apresentando-lhes propostas possíveis de estudo, tal como a variedade de materiais disponíveis e a entrevista com o professor, que também favoreceu tal desmistificação por se aproximarem da realidade de sua futura profissão.

Essa abordagem da $\mathrm{HO}$ veio colaborar com a discussão das necessidades para a disciplina CMPEM frente aos questionamentos dentro do curso e exigências para com o educador. Porém, entre outras possibilidades, a proposta da HO realizada tratou de aspectos necessários à formação, oportunizando, aos graduandos, contatos com as esferas de suas experiências até chegar às experiências discutidas e solidificadas em teorias.

Porém, ainda reconhecemos que o tempo de duração da disciplina é limitado (75 horas) ao considerarmos as carências dos acadêmicos. Assim, talvez seja mais viável que essa proposta se dê em paralelo às atividades presenciais da disciplina, de modo que, em sala de aula, as atividades matemáticas se deem com mais ênfase e com o acompanhamento da professora. 
Outra possibilidade, que encaramos com destaque, são as relações de prática estabelecidas por meio da experiência com o contato do professor em serviço por meio da entrevista e tratamento desta. Ao vivenciarem essa experiência, tornaram-se possíveis a reflexão e criticidade a partir daquela realidade, fazendo com que os estudantes saíssem de suas posições de estudantes e sinalizassem possibilidades para si em sua futura prática profissional, o que acham que podem/devem ou não fazer.

\section{Algumas considerações}

Em linhas gerais, podemos afirmar que as pesquisas de Tizzo (2014) e Flugge (2015) acenaram a $\mathrm{HO}$ como uma abordagem didático-pedagógica que valorizou o contato dos discentes das disciplinas envolvidas com experiências narradas por professores em exercício sobre situações escolares, e, também, promoveram aprendizagens e inversões de opinião, por parte dos acadêmicos, acerca de temas investigados, o que concordamos, deve caracterizar os processos de formação de professores (de Matemática). Devemos enfatizar que tais aspectos extrapolam, portanto, o Estágio Supervisionado, quando estratégias de formação com narrativas (orais e escritas) são realçadas nesses outros espaços disciplinares da licenciatura. Os recursos da $\mathrm{HO}$ mostraram-se instrumentos profícuos para auxiliar processos formativos voltados ao futuro professor de matemática, na medida em que permitiram um caminho de inscrição do percurso pessoal e profissional dos licenciandos na história, trazendo aportes para o desenvolvimento da compreensão crítica, no que tange à atuação desses futuros professores.

Com relação ao projeto maior, envolvendo a elaboração de estratégias com os recursos da História Oral para o processo de formação inicial de professores (de matemática ou que ensinam matemática), compreendemos que ambas as pesquisas aqui apresentadas constituíram-se em empreendimentos de diferentes possibilidades, dadas as distintas finalidades das disciplinas envolvidas. Entretanto, os resultados dessas duas experiências trazem contribuições para tal projeto e para a formação de professores (de Matemática), de um modo geral, por ensejarem uma autorreflexão produtiva e por conduzirem os estudantes futuros professores - envolvidos em ambas as atividades, a uma forma mais ativa de aprendizagem e pesquisa.

\section{Referências}


ABRAHÃO, M. H. M. B (Org.). A aventura (auto)biográfica: teoria e empiria. Porto Alegre: EDIPUCRS, 2004,

BOLÍVAR, A.; DOMINGO, J.; FERNÁNDEZ, M. La Investigación Biográfico-narrativa em educación: enfoque y metodologia. Madrid: La Muralla, 2002.

CORDEIRO, V. M. R.; SOUZA, E. C. de. (Org.). Memoriais, literatura e práticas culturais de escrita. Salvador: EDUFBA, 2010.

FLUGGE, F. C. G. Potencialidades das Narrativas para a Formação Inicial de Professores que Ensinam Matemática. 2015. 255f. Dissertação (Mestrado em Educação Matemática) - Instituto de Geociências e Ciências Exatas, Universidade Estadual Paulista, Rio Claro, 2015.

FIORENTINI, D. et al. Formação de Professores que ensinam matemática: um balanço de 25 anos da pesquisa brasileira. Educação em Revista. Belo Horizonte, n. 36, p.137-60, dez. 2002.

FIORENTINI, D. Uma história de reflexão e escrita sobre a prática escolar em matemática. In: FIORENTINI, D.; CRISTOVÃO, E. M. (Org.). Histórias e Investigação de/em Aulas de Matemática. Campinas: Alínea, 2006. p. 13-36.

GARNICA, A. V. M.; MARTINS, R. M. Avaliação de um Projeto Pedagógico para Formação de Professores de Matemática: um estudo de caso. Zetetiké, Campinas, v. 7, n. 12, p. 51-74, jul./dez. 1999.

GARNICA, A. V. M. Estacas em Paisagens Móveis: um ensaio a partir da narrativa de três professores de Matemática. In: TEIXEIRA, I. A. de C. et al (Org.). Viver e Contar: experiências e práticas de professores de Matemática. 1. ed. São Paulo: Editora Livraria da Física, 2012, p. 329-345. (Coleção Contextos da Ciência).

GARNICA, A. V. M. Cartografias Contemporâneas: mapear a formação de professores de Matemática. In: GARNICA, A. V. M. (Org.). Cartografias Contemporâneas: mapeando a formação de professores de Matemática no Brasil. Curitiba: Appris, 2014. p. 39-66.

GOMES, M. L. M. Matemática e escola: uma experiência integradora na licenciatura em matemática da Universidade Federal de Minas Gerais. Zetetiké, Campinas, v. 5, n.7, p. 95-109, jan./jun. 1997.

GOMES, M. L. M.; TIZZO, V. S.; SILVA, H. da. Narrativas Biográficas e Autobiográficas na (e para a) Formação de Professores. In: ENCONTRO NACIONAL DE EDUCAÇÃO MATEMÁTICA, 11. 2013, Curitiba. Anais... Curitiba: PUC-PR, 2013. p. 1-8.

GOMES, M. L. M. Narrativas Autobiográficas e História da Educação Matemática na Formação de Professores a Distância. In: ENCONTRO NACIONAL DE PESQUISA EM HISTÓRIA DA EDUCAÇÃO MATEMÁTICA, 2. 2014, Bauru. Anais... Bauru: Unesp - Faculdade de Ciências, 2014, p. 196-205.

MARTINS-SALANDIM, M. E. A Interiorização dos Cursos de Matemática no Estado de São Paulo: um exame da década de 1960. 2012. 379f. Tese (Doutorado em Educação Matemática) Instituto de Geociências e Ciências Exatas, Universidade Estadual Paulista, Rio Claro, 2012.

MEGID, M. A. B. A; FIORENTINI, D. Formação docente a partir de narrativas de aprendizagem. Interacções, Coimbra, v. 7, p. 178-203, 2011. 
MOREIRA, P. C. $3+1$ e suas (in)variantes (reflexões sobre as possibilidades de uma nova estrutura curricular na licenciatura em matemática). Bolema, Rio Claro, v. 26, n. 44, p. 1137-1150, dez. 2012.

NACARATO, A. M.; PASSEGGI, M. da C. Narrativas autobiográficas produzidas por futuras professoras: representações sobre a matemática escolar. Revista Educação PUC-Campinas, Campinas, v. 18, n. 3, p. 287-299, set./dez. 2013.

OLIVEIRA, M. C. A.; FRAGOSO, W. C. História da Matemática: história de uma disciplina. Revista Diálogo Educacional, Curitiba, v. 11, p. 625-643, set./dez. 2011.

RICOEUR, P. Narratividad, fenomenologia y hermenéutica. Anàlisi. Quaderns de comunicació y cultura, Barcelona, n. 25, p. 189-207, 2000.

SILVA, H. da; BARALDI, I. M.; GARNICA, A. V. M. Sentidos para a pesquisa com narrativas (em Educação Matemática). In: FLORES, C. R.; CASSIANI, S. (Org.). Tendências contemporâneas nas pesquisas em Educação Matemática e Científica: sobre linguagens e práticas culturais. Campinas: Mercado de Letras, 2013, p. 61-89.

SILVA, H. da. A História Oral como recurso no desenvolvimento na formação inicial e continuada de professores de Matemática. 2010, p. 1-19. Projeto de Pesquisa Trienal. Pró-Reitoria de Pesquisa,Universidade Estadual Paulista, Rio Claro, 2010.

SILVA, H. da. Integrando história oral e narrativas a abordagens pedagógicas problematizadoras na formação inicial de professores de matemática. Revista Educação PUC-Campinas, Campinas, v. 18, n. 3, p. 269-285, set./dez. 2013.

SOLIGO, R.; PRADO, G. do V. T. Quem Forma Quem, Afinal? In: VICENTINI, A. A. F. et al (Org.). Professor-Formador: histórias contadas e cotidianos vividos. 1. ed. Campinas: Mercado das Letras, 2008, p. 17-50.

SOUZA, L. A. História Oral e Educação Matemática: um estudo, um grupo, uma compreensão a partir de várias versões. 2006. 348f. Dissertação (Mestrado em Educação Matemática) - Instituto de Geociências e Ciências Exatas, Universidade Estadual Paulista, Rio Claro, 2006.

TIZZO, V. S.; SILVA, H. da. Sobre potencialidades da história oral como abordagem didáticopedagógica na disciplina Política Educacional Brasileira em um curso de licenciatura em matemática. In: ENCONTRO NACIONAL DE EDUCAÇÃO MATEMÁTICA, 11, 2013, Curitiba. Anais... Curitiba: PUC-PR, 2013. p. 1-16.

TIZZO, S. V. A História Oral como uma Abordagem Didático-Pedagógica na Disciplina Política Educacional Brasileira de um Curso de Licenciatura em Matemática. 2014. 345f. Dissertação (Mestrado em Educação Matemática) - Instituto de Geociências e Ciências Exatas, Universidade Estadual Paulista, Rio Claro, 2014.

TOGURA, T. C.; SOUZA, L. A. de. A História Oral: formação de professores de matemática. In: ENCONTRO SUL-MATO-GROSSENSE DE EDUCAÇÃO MATEMÁTICA, 11, 2012, Nova Andradina. Anais... Nova Andradina: UEMS 2012. p. 1-9. 